\title{
Differential survival throughout the full annual cycle of a migratory bird presents a life-history trade-off
}

\section{Evan R. Buechley ${ }^{1,2}$ (D) | Steffen Oppel ${ }^{3}$ (D) | Ron Efrat ${ }^{4}$ (D) | W. Louis Phipps ${ }^{5}$ (D) Isidoro Carbonell Alanís $^{6}$ | Ernesto Álvarez ${ }^{7}$ | Alessandro Andreotti ${ }^{8}$ Volen Arkumarev 9 (D) | Oded Berger-Tal ${ }^{4}$ (D) | Ana Bermejo Bermejo ${ }^{10}$ | Anastasios Bounas $^{11}$ (D) | Guido Ceccolini ${ }^{12}$ | Anna Cenerini ${ }^{12}$ | Vladimir Dobrev ${ }^{9}$ Olivier Duriez $^{13}$ (D) | Javier García ${ }^{14}$ (D) | Clara García-Ripollés ${ }^{15}$ | Manuel Galán ${ }^{7}$ | Alberto Gil $^{7}$ | Lea Giraud $^{16}$ | Ohad Hatzofe ${ }^{17}$ | Juan José Iglesias-Lebrija ${ }^{7}$ (D) | Igor Karyakin $^{18}$ (D) | Erik Kobierzycki ${ }^{19}$ | Elzbieta Kret $^{20}$ | Franziska Loercher ${ }^{5}$ |} Pascual López-López ${ }^{21}$ (D) | Ygal Miller ${ }^{17}$ | Thomas Mueller ${ }^{22,23}$ (i) | Stoyan C. Nikolov Javier de la Puente ${ }^{10}$ (D) | Nir Sapir ${ }^{24}$ (D) | Victoria Saravia ${ }^{11}$ | Çağan H. Şekercioğlü $25,26,27$ T. Scott Sillett ${ }^{1}$ (D) | José Tavares ${ }^{5}$ (D) | Vicente Urios ${ }^{28}$ | Peter P. Marra ${ }^{29}$ (D)

${ }^{1}$ Smithsonian Migratory Bird Center, Washington, DC, USA; ${ }^{2}$ HawkWatch International, Salt Lake City, UT, USA; ${ }^{3}$ Royal Society for the Protection of Birds, RSPB Centre for Conservation Science, Cambridge, UK; ${ }^{4}$ Mitrani Department of Desert Ecology, Jacob Blaustein Institutes for Desert Research, Ben-Gurion University of the Negev, Midreshet Ben-Gurion, Israel; ${ }^{5}$ Vulture Conservation Foundation, Zurich, Switzerland; ${ }^{6}$ SALORO, Salamanca, Spain; 7 GREFA (Grupo para la Rehabilitación de la Fauna Autóctona y su Hábitat) Majadahonda, Madrid, Spain; ${ }^{8}$ Italian Institute for Environmental Protection and Research (ISPRA), Ozzano Emilia, Italy; ${ }^{9}$ Bulgarian Society for the Protection of Birds/BirdLife Bulgaria, Sofia, Bulgaria; ${ }^{10}$ Bird Monitoring Unit, SEO/BirdLife, Madrid, Spain; ${ }^{11}$ Hellenic Ornithological Society/BirdLife Greece - Themistokleous 80, Athens, Greece; ${ }^{12}$ Association CERM Centro Rapaci Minacciati, Rocchette di Fazio (GR), Italy; ${ }^{13} \mathrm{CEFE}$, Univ Montpellier, CNRS, EPHE, IRD, Univ Paul Valery Montpellier 3, Montpellier, France; ${ }^{14}$ Department of Biodiversity and Environmental Management, University of León, León, Spain; ${ }^{15}$ Environment Science and Solutions, Valencia, Spain; ${ }^{16}$ Ligue pour la Protection des Oiseaux, Site Grands Causses, Peyreleau, France; ${ }^{17}$ Science Division, Israel Nature and Parks Authority, Jerusalem, Israel; ${ }^{18}$ Sibecocenter LLC, Novosibirsk, Russia; ${ }^{19}$ Nature en Occitanie, Coordination Technique Plan National d' Actions Vautour Percnoptère, Bruges, France; ${ }^{20}$ WWF Greece, Athens, Greece; ${ }^{21}$ Movement Ecology Lab, Cavanilles Institute of Biodiversity and Evolutionary Biology, University of Valencia, Paterna, Spain; ${ }^{22}$ Senckenberg Biodiversity and Climate Research Centre (SBiK-F), Frankfurt am Main, Germany; ${ }^{23}$ Department of Biological Sciences, Johann Wolfgang Goethe-University, Frankfurt, Frankfurt am Main, Germany; ${ }^{24}$ Department of Evolutionary and Environmental Biology and Institute of Evolution, University of Haifa, Haifa, Israel; ${ }^{25}$ School of Biological Sciences, University of Utah, Salt Lake City, UT, USA; ${ }^{26}$ College of Sciences, Koç University, Istanbul, Turkey; ${ }^{27}$ KuzeyDoğa Derneği, Kars, Turkey; ${ }^{28}$ Vertebrate Zoology Research Group, University of Alicante, Alicante, Spain and ${ }^{29}$ Department of Biology and McCourt School of Public Policy, Georgetown University, Washington, DC, USA

Correspondence

Evan R. Buechley

Email: ebuechley@gmail.com

Funding information

La salsepareille; Conservatoire des Espaces

Naturels PACA; Christensen Fund; USA

National Science Foundation; HawkWatch International; DREAL Nouvelle-Aquitaine;

Fondationd' entreprises Barjane; Kuzey Doğa; SALORO S.L.U.; Sigrid Rausing Trust; Whitley Fund for Nature; Vautours en Baronnies; National Geographic Society; Fundación Iberdrola España; NorthStar Science and Technology; Poison Sentinels Project of WWF/Spain; Turkey's Ministry

\section{Abstract}

1. Long-distance migrations are among the most physically demanding feats animals perform. Understanding the potential costs and benefits of such behaviour is a fundamental question in ecology and evolution. A hypothetical cost of migration should be outweighed by higher productivity and/or higher annual survival, but few studies on migratory species have been able to directly quantify patterns of survival throughout the full annual cycle and across the majority of a species' range.

2. Here, we use telemetry data from 220 migratory Egyptian vultures Neophron percnopterus, tracked for 3,186 bird months and across approximately $70 \%$ of the 
of Forestry and Water Affairs General Directorate of Nature Conservation and National Parks; Russian Raptor Research and Conservation Network; Associação Transumância e Natureza; Associação de Conservação da Natureza e do Património Rural; Sociedade Portuguesa para o Estudo da Aves; Israel Nature and Parks Authority; Vulture Conservation Foundation; Diputación Foral de Gipuzkoa; La Rioja Regional Government; Fundación Hazi; Junta de Castilla y León, Spain; Israeli Academy of Science's Adams Fellowship; German-Israeli Foundation for Scientific Research and Development, Grant/Award Number: I-1465-413.13/2018; Fundación Patrimonio Natural de Castilla y León; EDP Distribuição-Energia SA; Instituto da Conservação da Natureza e Florestas, Portugal; Guarda Nacional Republicana, Portugal; AG Leventis Foundation; MAVA Foundation; LIFE+, Grant/Award Number: LIFE 16 NAT/BG/000874, LIFE10 NAT/ BG/000152, LIFE14 NAT/PT/00855 and LIFE16 NAT/IT/000569; Ligue pour la Protection des Oiseaux; Saudi Aramco; Parc National des Pyrénées; Ben-Gurion University's Negev Fellowship; Nature en Occitanie; The Porsim Kanaf Project; Basque Government Predoctoral, Grant/ Award Number: 569382696; State Nature Reserve 'Dagestanskiy'

Handling Editor: Jason Chapman species' global distribution, to test for differences in survival throughout the annual cycle.

3. We estimated monthly survival probability relative to migration and latitude using a multi-event capture-recapture model in a Bayesian framework that accounted for age, origin, subpopulation and the uncertainty of classifying fates from tracking data.

4. We found lower survival during migration compared to stationary periods ( $\beta=-0.816$; $95 \%$ credible interval: -1.290 to -0.318 ) and higher survival on nonbreeding grounds at southern latitudes $\left(<25^{\circ} \mathrm{N} ; \beta=0.664 ; 0.076-1.319\right)$ compared to on breeding grounds. Survival was also higher for individuals originating from Western Europe ( $\beta=0.664$; 0.110-1.330) as compared to further east in Europe and Asia, and improved with age ( $\beta=0.030 ; 0.020-0.042$ ). Anthropogenic mortalities accounted for half of the mortalities with a known cause and occurred mainly in northern latitudes. Many juveniles drowned in the Mediterranean Sea on their first autumn migration while there were few confirmed mortalities in the Sahara Desert, indicating that migration barriers are likely species-specific.

5. Our study advances the understanding of important fitness trade-offs associated with long-distance migration. We conclude that there is lower survival associated with migration, but that this may be offset by higher non-breeding survival at lower latitudes. We found more human-caused mortality farther north, and suggest that increasing anthropogenic mortality could disrupt the delicate migration trade-off balance. Research to investigate further potential benefits of migration (e.g. differential productivity across latitudes) could clarify how migration evolved and how migrants may persist in a rapidly changing world.

\section{KEYWORDS}

Egyptian vulture, evolutionary ecology, life-history theory, migration cost, movement ecology, Neophron percnopterus, satellite telemetry, survival

\section{1 | INTRODUCTION}

The question of why animals migrate and how migration evolved is a central question in ecology (Berthold, 2001; Dingle, 1996). A variety of potential selective pressures that may drive the evolution of migration have been presented, including seasonality of resources, interspecific density-dependent effects, predation and parasitism (Alerstam \& Hedenstrom, 1998). Lack (1954) proposed a unifying theory suggesting that if the benefit-to-cost ratio of moving exceeds the ratio for staying, then migration will be favoured by natural selection. While these theories have gained support in the literature (e.g. McNamara et al., 2008), it has been difficult to estimate costs and benefits of migration for highly mobile species across vast geographies and throughout their full annual cycle (Marra et al., 2015).

Among long-lived species, adult survival contributes more to population growth than productivity (Crone, 2001; Sæther \& Bakke, 2000; Sutherland, 1996). However, survival is mostly inferred from re-sighting of marked animals at particular times of the year (Schaub \& Royle, 2014), which cannot resolve at which point in time mortality occurs between two subsequent observation periods (Marra et al., 2015). The fundamental prediction of migration theory that a survival cost of migration must be compensated by an increase in fitness elsewhere has therefore been very challenging to test (Sanz-Aguilar et al., 2015).

Recent studies have begun to examine the patterns of survival throughout the full annual cycle of migratory birds. These include studies based on resightings of marked individuals that are able to estimate apparent survival during different annual stages (e.g. Lok et al., 2015; Millon et al., 2019; Rockwell et al., 2017; Rushing et al., 2017; Sillett \& Holmes, 2002; Swift et al., 2020), as well as studies that have used global-scale remote-tracking systems to track individuals with great precision, thus enabling the determination of the timing and location of mortalities and, thus, estimation of true survival throughout the full annual cycle (e.g. Cheng et al., 2019; Klaassen et al., 2014; Oppel et al., 2015; Senner et al., 2019; Sergio, Tavecchia, et al., 2019). Together, these studies have provided evidence of differential survival by age (e.g. Rotics et al., 2016; Sergio, Tavecchia, et al., 2019), direct survival costs associated with 
migration (e.g. Cheng et al., 2019; Klaassen et al., 2014; Rushing et al., 2017) and carryover effects from conditions in one life stage impacting survival in another (e.g. Duriez et al., 2012; Rockwell et al., 2017; Swift et al., 2020). However, quantifying the effects on survival of migratory versus stationary periods and breeding versus non-breeding latitudes in a single analytical framework would allow for an evaluation of one of the trade-offs associated with migration.

Here, we studied how the survival of a migratory bird related to behaviour (migratory vs. stationary periods) and geography (high vs. low latitude, representing breeding and non-breeding grounds, respectively) throughout the full annual cycle and across approximately $70 \%$ of the species' global distribution, using satellite telemetry assembled through a large research collaboration. We studied the Egyptian vulture Neophron percnopterus, an endangered longdistance migratory raptor that ranges across much of southern Europe, northern Africa, the Middle East and Central and South Asia (BirdLife International, 2020). Migratory Egyptian vultures regularly travel $>4,000 \mathrm{~km}$ between northern breeding and southern wintering grounds, and use several distinct migratory flyways (Phipps et al., 2019). Although patterns in survival have been investigated separately for subpopulations of this species (Grande et al., 2009; Oppel et al., 2015; Sanz-Aguilar et al., 2015, 2017), there has never been a formal comparison across the majority of the species' range using a unified analytical framework.

We estimated monthly survival probability relative to migration and latitude for 220 individual Egyptian vultures that were satellitetracked within the last two decades (2007-2020) using a multi-event model while accounting for age, origin (wild or captive-bred) and the geographical source population of each individual. Our model accounted for the fact that the fates of satellite-tracked individuals can vary from known (bird recovered dead) to unknown (signal lost) by including fate uncertainty in the probability of a bird being alive in a given month. Thus, this work provides a conservative quantitative estimate of true survival throughout the full annual cycle and across the majority of the range of a migratory bird, thereby advancing our understanding of the ecological trade-offs associated with migration.

\section{2 | MATERIALS AND METHODS}

\section{1 | Data acquisition}

Between 2007 and 2020, 220 Egyptian vultures were fitted with satellite tracking devices in Europe, the Middle East and Africa (e.g. Ceccolini et al., 2009; Karyakin et al., 2018; Phipps et al., 2019). All individuals were migratory, with temperate breeding grounds in Europe and the Middle East and wintering grounds in Sub-Saharan Africa and the southern Arabian Peninsula. At the time of transmitter deployment, 152 birds were juveniles ( $\leq 18$ months), and 68 were immatures/adults (>18 months). However, as several juvenile birds aged into the older age class over the course of the study, our final dataset included 1,004 juvenile bird months and 2,182 immature/adult bird months. Tagged birds included 81 captive-raised individuals that were released as part of conservation projects aimed at population reinforcement and 14 individuals of wild origin that were released with tracking devices after being held in captivity for rehabilitation. Tags were similar across age classes and subpopulations, weighing between 16 and $48 \mathrm{~g}$ (approximately $1 \%-2 \%$ of body mass) and fitted in either backpack $(n=134)$ or leg-loop $(n=86)$ harness configurations (Anderson et al., 2020). We expect the tagging of vultures with transmitters to have little or no impact on survival (Bodey et al., 2018; Sergio et al., 2015), and although we cannot rule out the possibility of some effect on absolute survival, any effect is unlikely to affect our evaluation of monthly survival across migration or latitude within the same individual. Tracking data were primarily stored in and accessed from Movebank (www.movebank.org; Kranstauber et al., 2011) with some data contributed directly by co-authors. Summaries of the data by study (Table S1), subpopulation (Table S2), year (Table S3), and transmitter type and attachment method (Table S4) are available as Supporting Information.

\subsection{Data processing}

All data processing steps were completed in R, version 3.6.1 ( $\mathrm{R}$ Core Team, 2019). We censored data to include only the first location from each individual each day (Phipps et al., 2019). We then used the ADEHABITATLT package (Calenge, 2006) to compute net displacement between successive points, which was used to delineate migration periods from stationary periods on breeding and wintering grounds. For each month of the study, we evaluated whether each bird exhibited migration in that month, as indicated by directional travel (i.e. net displacement) away from the current stationary range and towards the target range (Phipps et al., 2019). While birds may have migrated only part of a month, we classified and estimated survival at a monthly scale to provide a conservative test of the survival cost associated with migration. Of 469 migrations, 57\% were 1 month, 39\% were 2 months, $3 \%$ were 3 months and $3(0.6 \%)$ were $4-5$ months.

To describe when and where mortality occurred, the fate of each individual vulture was determined by a combination of direct observations and review of tracking data. We classified the fate for each vulture in each month it was tracked into five categories: (a) functional tags on a moving animal ('alive'); (b) transmitter data that indicated mortality (last transmissions did not travel $>100$ m over two or more days or transmission terminated over the Mediterranean Sea indicating likely drowning) but which could not be verified in person ('likely dead'); (c) bird carcass or transmitter recovered by people who confirmed that the bird had perished ('confirmed dead'); (d) bird observed alive without corresponding transmitter data ('confirmed transmitter failure') and (e) transmission ceased with no indication of mortality and the bird was not observed thereafter ('unknown').

For those birds that had ceased transmissions by the end of our acquisition period (October 2020), we summarized the distribution of fates in relation to breeding subpopulation, age-class ( $\leq 18$ months or $>18$ months), origin (wild or captive-bred) and stage of the annual 
cycle (breeding, fall migration, non-breeding or spring migration). We set the age cut-off at 18 months because mortality is expected to be much higher during the first migration and juvenile life stage, which lacks return migration from wintering grounds to higher latitudes (Grande et al., 2009; Oppel et al., 2015; Sergio et al., 2014). Breeding subpopulations were separated into two groups, with individuals from breeding grounds in Western Europe that migrated through the Strait of Gibraltar (France, Portugal and Spain) grouped as 'western', while the rest of the birds, originating in Central and Eastern Europe, the Caucasus and the Middle East were grouped as 'eastern'. This grouping was based on differences in migration ecology and population trends. Phipps et al. (2019) demonstrated that the migrations of Egyptian vultures from the eastern Mediterranean Basin and the Middle East were up to twice as long and less direct than those from Western Europe, and the Western European subpopulation is broadly stable (Del Moral \& Molina, 2018; Oppel \& Margalida, 2020), whereas all other studied subpopulations are declining (Arkumarev et al., 2018; Karimov \& Mammadov, 2019; Liberatori \& Penteriani, 2001; Mayrose et al., 2017; Velevski et al., 2015). Finally, because the raw number of fates does not account for the amount of time birds spend in certain regions, we also summarized the number of 'losses' in relation to the total amount of time spent by tracked birds in three geographical zones, namely the sub-Saharan wintering areas (latitude $<20^{\circ} \mathrm{N}$ ), the Sahara and Arabian deserts (latitude $20-30^{\circ} \mathrm{N}$ ), and European and Middle Eastern breeding grounds $\left(>30^{\circ} \mathrm{N}\right)$.

\section{3 | Survival analyses}

We estimated monthly survival probability of tracked birds using a multi-event capture-recapture model (Genovart et al., 2012; Zúñiga et al., 2017) that included five observable events (described as 'fates' above), as well as three true states, namely, that (a) an animal was alive with a functioning tag; (b) alive without a functioning tag (transmitter failure) or (c) dead.

The probability of an animal to be in any of the three latent true states given that it was observed in one of the five observation events was modelled based on the probability to receive data from an animal, the probability for a tag to fail and the probability to find a dead animal once it died. The probability of tag failure was modelled as a function of tag age and transmission history. The probability to recover a dead bird was modelled as a function of latitude because the much higher observer density and the more accessible terrain at northern latitudes (i.e. Europe) made it more likely that dead birds would be recovered.

We were mostly interested in assessing whether survival differed between migratory and stationary periods and between breeding and non-breeding grounds. We therefore estimated the probability to survive from 1 month to the next, based on whether the bird migrated in that month and whether the bird was north or south of $25^{\circ} \mathrm{N}$ (i.e. the approximate central latitude of the Sahara and Arabian Deserts). We chose a monthly interval for survival estimation because the very high (>99\%) survival over shorter intervals for a long-lived species renders the estimation of parameter uncertainty problematic (Lebreton et al., 1992), and a month including 'migration' would also include stopovers and carry-over effects and thus provide a more conservative test of the effect of migration. We evaluated the latitudinal effect only for birds older than 18 months because we did not mark fledglings in Africa, and the latitudinal effect would therefore be confounded by generally lower survival during the first 1.5 years of life. Besides these predictors of interest, we also accounted for other known sources of variation in survival probability. We accounted for breeding subpopulation by classifying birds as either 'western' or 'eastern' (as justified above). We included age as a continuous variable up to a maximum value of 54 months, that is, when Egyptian vultures reach full adult plumage because survival probability in migratory raptors is known to increase with age (Grande et al., 2009; Sergio et al., 2014). Although survival may decrease at old age, we were unable to test for such an effect because we were not able to ascertain the age of birds with adult plumage and we only tracked adult birds for a maximum of 8 years. Given the typically long life span of Egyptian vultures (at least 20 years), we consider it unlikely that the late onset of senescence that has been demonstrated in similarly long-lived vultures (>28 years; Chantepie et al., 2016) had a material effect on our conclusions (Nisbet, 2001). We therefore kept our numerical variable 'age' constant at 54 months for all birds that passed this age threshold.

We also included a factor that specified whether birds originated from the wild or were captive-bred, given that captive-bred birds often have lower survival in the wild (Evans et al., 2009; Mihoub et al., 2014; Nicoll et al., 2004; Smart et al., 2010). Finally, given that our data were accumulated over a time span of 13 years, we accounted for the possibility of temporal variation in survival probability due to environmental influences by including a random effect that allowed survival probability to vary in each year.

We used a Bayesian framework for inference and parameter estimation. The code of our model is available in Appendix 1. We used a mildly informative positive prior for the effect of the western subpopulation, because this population has a shorter migration and is generally stable and thus likely has higher survival than subpopulations farther east (Oppel \& Margalida, 2020; Phipps et al., 2019). We used vague normally distributed priors for all other parameters, and conducted a prior sensitivity test to ensure that biologically plausible survival estimates resulted from our prior distributions, and that a different choice of priors did not affect our conclusions (Banner et al., 2020). We fit the survival model in the program JAGS (Plummer, 2015), called from R via the package JAGsUI (Kellner, 2016). We ran three Markov chains for 25,000 iterations each, discarded the first 5,000 iterations and used every fifth iteration for inference. Convergence of the three chains for all monitored parameters was visually inspected using trace plots and tested using the GelmanRubin diagnostic (Brooks \& Gelman, 1998). We present posterior estimates of monthly survival with $95 \%$ credible intervals for our variables of interest. We also present median parameter estimates $(\beta)$ for covariates on the logit scale with $95 \%$ credible intervals and 
assume that covariates did not affect monthly survival probability if the $95 \%$ credible intervals included zero.

To facilitate interpretation and comparison with other survival estimates, we extrapolated our monthly survival probabilities to annual survival probabilities. To estimate annual survival, we specified age (in months), subpopulation, captive or wild origin, latitude (north or south of $25^{\circ} \mathrm{N}$ ) and migratory stage for each month of the year, estimated monthly survival based on our model, and then multiplied these 12 monthly survival probabilities. To account for migration, we assigned one migratory month to juveniles, since they generally do not migrate out of Africa in their second calendar year, and two migratory months and 6 months at lower latitude for adults to account for fall and spring migration (Phipps et al., 2019).

\section{3 | RESULTS}

\subsection{Dataset and fates}

Tagged individuals ranged over nearly 7,000 longitudinal kilometres from Western Africa to the Arabian Peninsula, and >4,500 latitudinal kilometres from Europe to sub-Saharan Africa, covering approximately $70 \%$ of the species' current global distribution (Figure 1). Of the 220 birds, 173 were from eastern breeding subpopulations (i.e. Italy, the Balkans, Middle East or Caucasus; 92 wild and 81 captivebred) and 47 were from breeding subpopulations in Western Europe (i.e. Spain, France, Portugal; all wild). Individuals were tracked for a median of 6 months, with a range of 1-98 months (i.e. over 8 years), and a total of 3,186 bird months including 469 migrations. Final fate classifications at the end of the study period included 72 individuals alive, 52 confirmed dead, 38 likely dead, 8 confirmed transmitter failures and 50 unknowns (Figure 1).

There were proportionally more likely and confirmed mortalities from the eastern as compared to western subpopulations (Figure 1; Table S5), more for juveniles, and more during fall migration than any other annual stage (Figure 1), despite individuals spending less time on migration than on breeding or non-breeding grounds. Likely and confirmed mortalities were primarily concentrated in the northeastern part of the study region, particularly the eastern Mediterranean Basin. We recorded few mortalities in the Sahara Desert despite many birds crossing the desert twice per year (Figure 1). However, several unknown fates were recorded at the periphery of the desert, some of which may reflect the last recorded positions of individuals before mortalities that could have occurred in the Sahara. When corrected for the time birds spent in different geographical regions, the number of unknown fates per tracking year was similar across regions while the number of confirmed deaths was proportionally greater further north (Figure S1). In all, 17 individuals had their last positions terminate over the Mediterranean Sea, and thus likely drowned (i.e. Oppel et al., 2015). Additionally, nine individuals were confirmed to have died from electrocution or collision with energy infrastructure, seven were persecuted by humans (shot or trapped), six died of seemingly natural causes (four exhaustion, two predation), six were poisoned, two
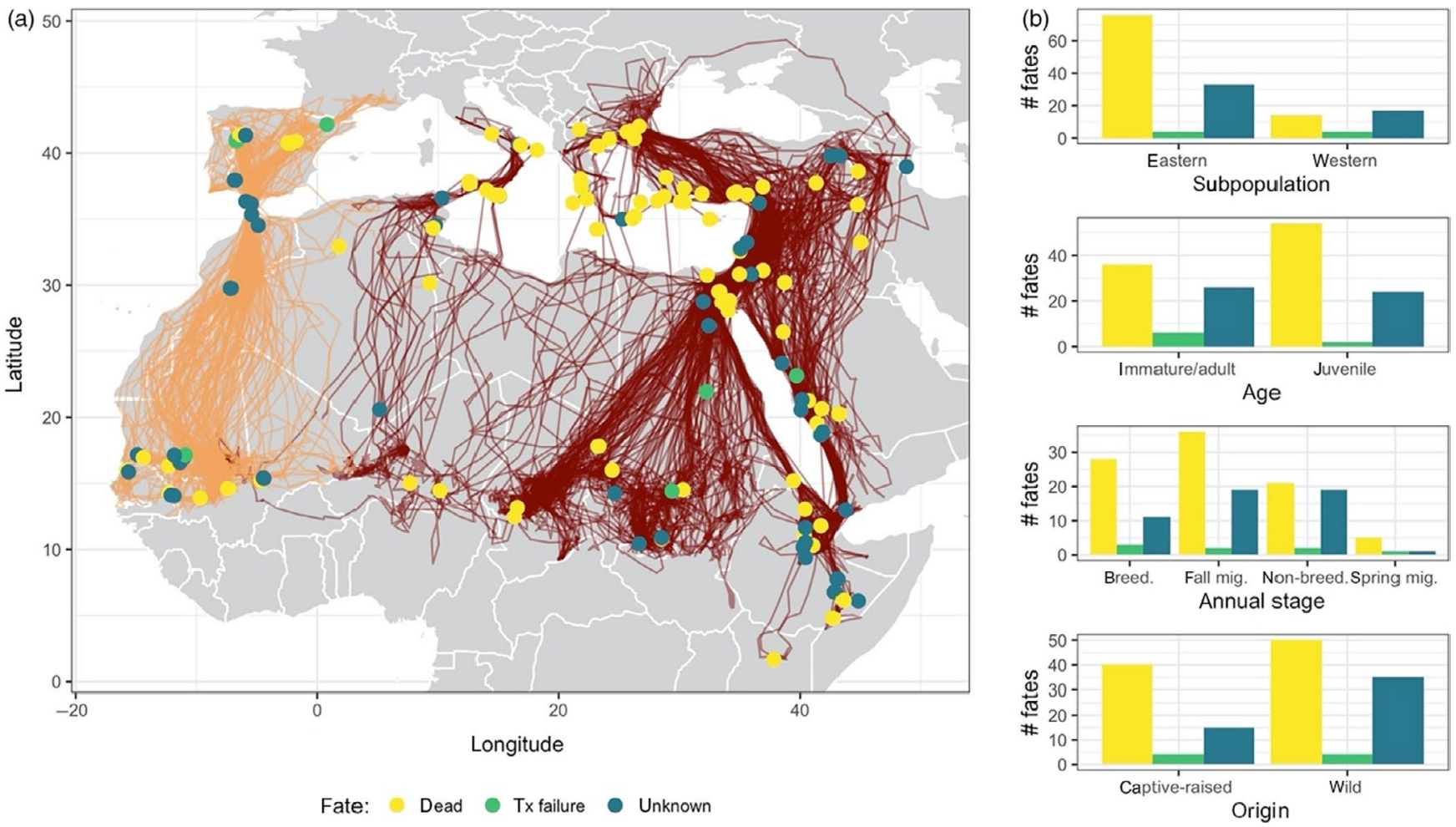

FIGURE 1 Overview of tracking data and locations where lost individuals were last recorded colour-coded according to their respective fate. For clarity here, fates classified as either 'likely dead' or 'confirmed dead' were grouped as 'dead'. Tracks are colour-coded by geographical subpopulation (i.e. 'western' or 'eastern') 
died from train collision and for the remaining 43 individuals the causes of death were unknown (Table S5). Overall, when including birds that likely drowned, $51.1 \%$ (24 of 47 ) of mortalities with a known cause were anthropogenic.

\section{2 | Survival probability throughout the annual cycle}

Using data from 220 individuals collectively tracked for 3,186 bird months, we found reduced survival probability during months in which birds migrated as compared to stationary months, and higher monthly survival at latitudes $<25^{\circ} \mathrm{N}$ as compared to farther north for birds older than 18 months (Table 1), but the uncertainty in this

TAB LE 1 Median, lower (Icl) and upper (ucl) 95\% credible limits of parameter estimates affecting monthly true survival probability of satellite-tracked Egyptian vultures, estimated with a multi-event model accounting for uncertainty of assigning fates of birds for which the signal was lost. Note that the age of birds was specified in months (1-54) while all other covariates were binary

\begin{tabular}{|lccc|}
\hline Parameter & Median & Icl & ucl \\
\hline $\begin{array}{l}\text { Monthly survival } \\
\text { (intercept) }\end{array}$ & 2.884 & 2.387 & 3.390 \\
\hline Migration & -0.816 & -1.290 & -0.318 \\
\hline Captive-bred & -0.275 & -0.745 & 0.184 \\
\hline Western Europe & 0.664 & 0.110 & 1.330 \\
\hline Age (in months) & 0.030 & 0.020 & 0.042 \\
\hline Latitude $<25^{\circ} \mathrm{N}$ & 0.664 & 0.076 & 1.319 \\
\hline
\end{tabular}

Note: All estimates are on the logit scale. effect was greater than for the migration effect. Monthly survival was also higher for Egyptian vultures from Western Europe, and increased with age (Table 1; Figure 2). Birds of captive-bred origin tended to have marginally lower survival, but the uncertainty in this effect was larger than the mean effect size (Table 1).

Estimated survival probability during months that included migration was 0.905 (median, 0.803 lower credible limit, 0.966 upper credible limit) compared with 0.955 (0.909-0.984) during a stationary month at northern latitudes for juveniles in the first month after fledging, which gradually increased to 0.979 (0.947-0.993) during migration compared to $0.990(0.978-0.997)$ at northern latitudes and 0.995 (0.988-0.998) at southern latitudes for stationary adult vultures (Table S6). Based on these estimates of monthly survival

TABLE 2 Extrapolated annual survival probability (median $\pm 95 \%$ credible limits) for juvenile and adult Egyptian vultures from two geographical subpopulations. Annual survival estimates were derived from monthly estimates and extrapolated based on model predictions for 12 months of the year and accounting for typical geographical movements of each subpopulation. Reported estimates are median survival, and lower (Icl) and upper (ucl) credible limits

\begin{tabular}{llllll} 
Population & Age class & Origin & $\begin{array}{l}\text { Survival } \\
\text { (median) }\end{array}$ & $\begin{array}{l}\text { Survival } \\
\text { (Icl) }\end{array}$ & $\begin{array}{l}\text { Survival } \\
\text { (ucl) }\end{array}$ \\
\hline Eastern & Adult & Captive & 0.861 & 0.767 & 0.917 \\
Eastern & Adult & Wild & 0.892 & 0.827 & 0.936 \\
\hline Eastern & Juvenile & Captive & 0.458 & 0.283 & 0.604 \\
Eastern & Juvenile & Wild & 0.547 & 0.393 & 0.681 \\
Western & Adult & Wild & 0.943 & 0.896 & 0.971 \\
Western & Juvenile & Wild & 0.731 & 0.569 & 0.850 \\
\hline
\end{tabular}

FIGURE 2 Predicted median monthly survival probability (with 95\% credible intervals) of satellite-tracked Egyptian vultures during migration and while at different latitudes (on breeding grounds north of $25^{\circ} \mathrm{N}$, or on non-breeding grounds south of $25^{\circ} \mathrm{N}$ ) estimated from a multi-event model accounting for captive origin, age and geographical subpopulation. Note that survival of young birds at southern latitudes was not estimated because our marking efforts of young birds were concentrated in northern latitudes

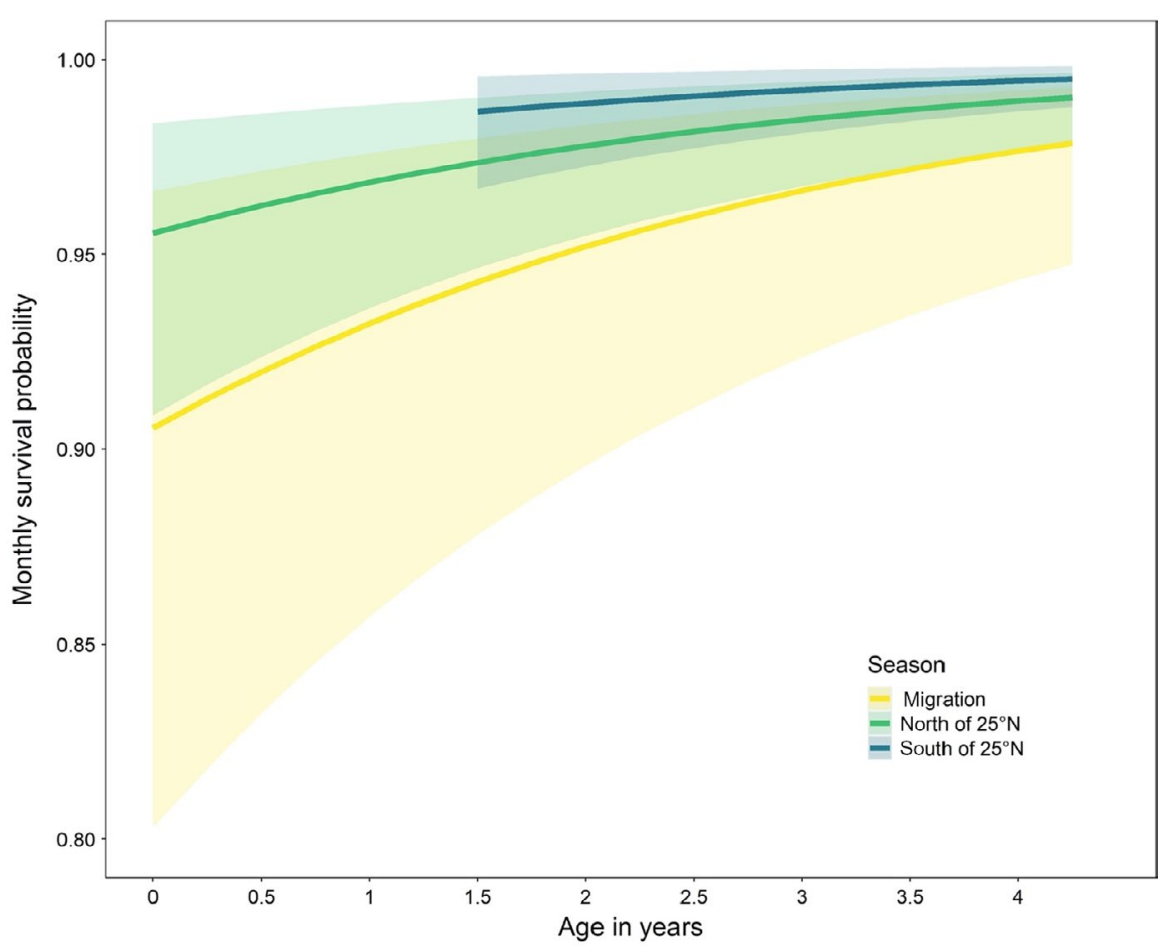


probability, we extrapolated annual survival probabilities to range from 0.458 for captive-bred juveniles from the eastern subpopulation to 0.943 for wild adults from the western subpopulation (Table 2).

\section{4 | DISCUSSION}

We revealed broad patterns in survival across most of the range of a long-distance soaring migrant bird, the Egyptian vulture. We showed that survival was lower during months when a bird migrated as compared to stationary periods, and higher on nonbreeding grounds in Sub-Saharan Africa as compared to breeding grounds in southern Europe, the Caucasus and the Middle East. This result indicates that there is a direct survival cost associated with long-distance migration, but that this lower survival during migration could be offset by the higher survival at southern nonbreeding grounds. These results are consistent with theoretical predictions about the evolution and maintenance of migratory systems (Alerstam \& Hedenstrom, 1998; Salewski \& Bruderer, 2007; Swift et al., 2020), and enable future quantitative predictions about the increase in productivity that would favour the evolution of migratory populations from stationary populations.

The higher survival at southern non-breeding grounds is not only of ecological and evolutionary relevance but also has implications for the conservation of migratory species. The population declines of many long-distance migratory birds are often presumed to be a consequence of deteriorating conditions at non-breeding areas (Sanderson et al., 2006; Vickery et al., 2014), but, despite large uncertainty in the latitude parameter, we found that proportionally more mortalities occurred farther north. We also found that approximately half of the mortalities for which a cause could be inferred were related to human activities or infrastructure (Table S5). This suggests that the delicate trade-off that currently exists between the costs and benefits of migration could be easily disrupted by an increasing level of human-caused mortality anywhere along the migratory flyway.

Our results are consistent with recent studies that have shown that migratory birds tend to experience a direct survival cost associated with migration (e.g. Cheng et al., 2019; Klaassen et al., 2014; Rushing et al., 2017), or show differences in seasonal survival between breeding and non-breeding seasons (Duriez et al., 2012; Robinson et al., 2020; Swift et al., 2020). For example, Klaassen et al. (2014) found daily mortality rates about six times higher on spring migration compared to the stationary summer period for three species of raptors migrating between Europe and Sub-Saharan Africa. In addition, Senner et al. (2019) also found high mortality for a shorebird during spring migration in the Sahara, whereas we found very few mortalities in the Sahara, despite our dataset including 323 Sahara crossings.

The apparently higher survival during the Sahara crossing of Egyptian vultures as compared to other birds may be attributable to species-specific behavioural adaptations (e.g. Efrat et al., 2019).
Thus, what constitutes a natural barrier that incurs a significant survival cost on migration is likely species-specific. The most prominent natural barrier that reduced survival during migration for Egyptian vultures was the Mediterranean Sea (Oppel et al., 2015). Although some raptor species are able to effectively cross large water bodies (e.g. Duriez et al., 2018; Monti et al., 2018), this is evidently challenging for thermal-soaring migrants like vultures (Agostini et al., 2015; Panuccio et al., 2012). However, the mortality associated with this natural barrier was limited to young and inexperienced birds (Table S5), which is consistent with other studies that show that the first autumn migration is the riskiest period for juvenile birds (Cheng et al., 2019).

The magnitude of the risk of a natural migration barrier to young birds on their first migration was particularly evident when comparing the annual survival of young birds between geographical subpopulations (Table 1). The higher survival of the western European birds may be explained by the more direct migration with a very short sea crossing at Gibraltar (Phipps et al., 2019), and the fact that anthropogenic mortalities were higher in the east and included many immature/adult birds (Figure 1; Table S5). These two factors may reduce survival and recruitment sufficiently to explain why all breeding subpopulations are declining apart from those in Western Europe, which are stable or increasing (Arkumarev et al., 2018; Karimov \& Mammadov, 2019; Liberatori \& Penteriani, 2001; Oppel \& Margalida, 2020; Velevski et al., 2015). Different exposure to both natural and anthropogenic threats may also explain the higher annual survival found in mark-resight studies for resident island populations compared to continental migrant populations of Egyptian vultures (Sanz-Aguilar et al., 2015). However, our study suggests that the survival cost of migration for adult birds might be offset by their higher survival at lower latitudes during winter than at northern latitudes. This result is inconsistent with higher annual survival of resident populations at northern latitudes. We therefore caution that our conclusions of the relative survival benefit of migration rest on the assumption that monthly survival probability at northern latitudes outside of the breeding season is not higher than during the breeding season. We encourage tests of this hypothesis with data that may become available in the near future (Morant et al., 2020).

We also caution that the effect sizes that we found for the survival differences between migration and stationary periods and north and south latitudes were surrounded by large uncertainty. This uncertainty was a consequence of several confounding variables (like age, and geographical and captive origin) but also due to our framework that incorporated the uncertainty in the actual fate of birds when transmitter signals were lost. Previous studies either assumed that lost signals indicated death under certain conditions (e.g. Klaassen et al., 2014), or relied on data collected by the transmitters to inform mortality assessments (Sergio, Tanferna, et al., 2019; Sergio, Tavecchia, et al., 2019). We also included information from transmitters, but treated the fate of many birds for which the signal was lost as unknown. The uncertainty in our parameter estimates therefore appropriately accounts for the problem that it is not always possible to know the fates of satellite-tracked animals. Nonetheless, despite 
the large uncertainty, our study indicates that survival at southern non-breeding grounds is higher than at northern breeding grounds and therefore presents a potential trade-off with the survival cost of long-distance migration.

The regions south of the Sahara that were used by non-breeding birds in our sample also have breeding populations of Egyptian vultures, which may have been the original source populations from which migratory populations evolved (Rappole \& Jones, 2002; Zink, 2002). Although our study indicates a potential survival tradeoff, the complete cost-benefit trade-off of migration is difficult to quantify because it would require an evaluation of all factors contributing to fitness, including both survival and productivity. Our finding that survival is higher at southern latitudes suggests that migrating to northern breeding grounds should facilitate higher productivity than breeding at southern latitudes, to compensate for the migration cost. However, we also show that many mortalities occurring at northern breeding grounds were human-induced in our study, which may not always have occurred at this intensity in the past (Arrondo et al., 2020). Thus, increased human pressure at northern breeding grounds may affect the cost-benefit trade-off of migration, and understanding both survival and productivity of resident populations would further illuminate the fitness trade-offs associated with long-distance migration (Sanz-Aguilar et al., 2015). The delicate balance between the cost and benefit of migration may be disrupted by increasing anthropogenic mortality along a migratory route, and warrants further research to identify possible changes in the maintenance of migration systems due to recent anthropogenic or environmental changes (Wilcove \& Wikelski, 2008).

\section{ACKNOWLEDGEMENTS}

Balkans and Caucasus data: We thank our collaborators including Kuzey Doğa Society (Turkey), Iğdır Directorate of Nature Conservation and National Parks (Turkey), American University of Armenia, Ethiopia Wildlife Conservation Authority, Ethiopia Wildlife and Natural History Society, Emrah Çoban, Lale Aktay, Kayahan Ağırkaya, Berkan Demir, Mete Türkoğlu (Turkey); Karen Aghababyan, Anush Khachatrian, Garo Kurginyan (Armenia); Sisay Seyfu, Alazar Daka Ruffo, Yilma Dellelegn Abebe, Girma Ayalew, Ahmed Endris, Lubomir Peske (Ethiopia); Svetoslav Spasov, Ivaylo Angelov, Saniye Mumun, Dobromir Dobrev, Tsvetomira Angelova, Stoycho Stoychev, Ewan and Jenny Weston, Emil Yordanov, Anton Stamenov, Atanas Delchev (Bulgaria), Vasilis Sideris, Giannis Chondros, Christos Lambris, Antonis Vroikos, Dimitris Vavylis, Angelos Evangelidis (Greece), Mirjan Topi (Albania), Metodija Velevski and Zlatko Angeleski (North Macedonia). This work was financially supported by Saudi Aramco, the LIFE+ projects LIFE10 NAT/BG/000152 and LIFE 16 NAT/BG/000874 funded by the European Union and co-funded by the AG Leventis Foundation and MAVA, the US National Science Foundation, the Christensen Fund, National Geographic Society, Sigrid Rausing Trust, the Whitley Fund for Nature, Kuzey Doğa's donors (in particular Bilge Bahar, Devrim Celal, Sehaişsmen, Ömer Külahçıoğlu, Lin Lougheed, Burak Över, Batubay Özkan, Alan Peterson and Suna Reyent), and HawkWatch
International and its donors (in particular Nancy and John Matro and Julia Shaw). State Nature Reserve 'Dagestanskiy' and Russian Raptor Research and Conservation Network supported work in Dagestan. We are grateful to Turkey's Ministry of Forestry and Water Affairs General Directorate of Nature Conservation and National Parks and NorthStar Science and Technology for donating transmitters.

Central Mediterranean data: We thank Arianna Aradis, Andrea Ferri, Maria Angela Francione and Matteo Visceglia. The release of captive-bred birds in Italy in 2018-2020 was financially supported by the EU-funded LIFE Egyptian vulture (LIFE16 NAT/IT/000569) and some of the tags were provided by MAVA and VCF. CERM provided the captive-bred birds to be released.

Western Europe data: For deployments in Spain we thank: L. Bolonio, J. de Lucas, V. García, R. Ibáñez, M. Nieto, and A. Vela in Castellón and Guadalajara provinces; Luis Lopo, Ignacio Gámez, Francisco Javier Robres, Sandra Vela, Lidia Roncero, Diego García, Sergio Mikolta, Miguel Ángel Elvira, Carlos Fernández, Sara Josefa Herrero, Álvaro Alonso, Eduardo Miera and Miguel Ángel Marín in La Rioja; José María Fernández, Iñigo Mendiola, Ibai Aizpuru, Fermín Ansorregi, Aitor Galdos, Aitor Lekuona, Mikel Olano, Jon Ugarte, Haritz Beñaran and Javier Vázquez in Guipúzcoa; María José Herrero and Juan Carlos Perlado in Segovia; Manuel Aguilera and Ángela García in Huesca; special thanks to José Francisco Pedreño that collaborated in the fieldwork in La Rioja, Guipúzcoa, Segovia and Huesca; Saloro S.L.U. contributed data from the Duero region of Spain; the GREFA veterinary team and contributors. For deployments in Portugal, we thank EU-funded LIFE Rupis Project partners: Sociedade Portuguesa para o Estudo da Aves; Associação Transumância e Natureza; Associação de Conservação da Natureza e do Património Rural; Guarda Nacional Republicana, Portugal; Fundación Patrimonio Natural de Castilla y León; EDP Distribuição-Energia SA; Instituto da Conservação da Natureza e Florestas, Portugal; Junta de Castilla y León, Spain; the MAVA Foundation. Also, the collaboration of Víctor García Matarranz (Ministerio para la Transición Ecológica y el Reto Demográfico, Spain) and Lubomír Peške. In France, the telemetry program was coordinated by the National Action plan for the Egyptian Vulture, and was supported by Nature en Occitanie, Parc National des Pyrénées, LPO, La salsepareille, Conservatoire des Espaces Naturels PACA, Vautoursen Baronnies DREAL Nouvelle-Aquitaine, and Fondation d'entreprises Barjane funded deployments in France. Special thanks to Cécile Ponchon, Didier Peyrusqué and Guillaume Fréchet for their assistance in France. Deployments of transmitters in Portugal were funded by the EU-funded LIFE Rupis project (LIFE14 NAT/PT/00855); SALORO S.L.U. funded the deployment of transmitters in the Duero region of Spain; JE was supported by Basque government predoctoral grant (grant number: 569382696); GREFA (Grupo para la Rehabilitación de la Fauna Autóctona y su Habitat) Endangered Species Monitoring Project together with Poison Sentinels Project of WWF/Spain. In Spain, the Migra Program of SEO/BirdLife (www.migraciondeaves.org/en/) deployed transmitters in collaboration with Fundación Iberdrola España, and were funded by La Rioja Regional Government in 
La Rioja, and Fundación Hazi and Diputación Foral de Gipuzkoa within the Interreg POCTEFA-ECOGYP project in Guipúzcoa.

Israel data: We thank the Israel Nature and Parks Authority (INPA) for their support of this project and Avishai Bar-on and Sappir Simchi for spearheading the captive-breeding of raptors in Israel. We also thank the many people who helped with field work, especially to Walter Neser, Korin Reznikov and Nili Anglister. The conservation of vultures in Israel, including GPS tagging was supported by the Porsim Kanaf project. This work was also supported by grant no. I-1465-413.13/2018 of the German-Israeli Foundation for Scientific Research and Development (GIF). RE is supported by the Israeli Academy of Science's Adams Fellowship and the Ben-Gurion University's Negev Fellowship.

\section{AUTHORS' CONTRIBUTIONS}

E.R.B., S.O., R.E., and P.P.M. conceived of the study; E.R.B., S.O., and R.E. developed the methodology and co-led the writing of the manuscript; S.O. led the survival modelling analyses, with input from E.R.B. and R.E. All other authors contributed tracking data, provided feedback on manuscript drafts and gave final approval for publication.

\section{DATA AVAILABILITY STATEMENT}

The data and code to replicate the results of this study are available at the following archived repository https://doi.org/10.5281/ zenodo.4514124 (Oppel, 2021).

\section{ORCID}

Evan R. Buechley (iD https://orcid.org/0000-0001-5180-4824 Steffen Oppel (iD https://orcid.org/0000-0002-8220-3789 Ron Efrat (iD https://orcid.org/0000-0002-6129-0596 W. Louis Phipps (iD https://orcid.org/0000-0003-0400-2014 Alessandro Andreotti iD https://orcid.org/0000-0002-0020-0569 Volen Arkumarev (iD https://orcid.org/0000-0003-1146-5594 Oded Berger-Tal iD https://orcid.org/0000-0002-7396-456X Anastasios Bounas (iD https://orcid.org/0000-0002-6724-0151 Olivier Duriez (iD https://orcid.org/0000-0003-1868-9750 Javier García (iD https://orcid.org/0000-0001-9641-0028 Juan José Iglesias-Lebrija (iD https://orcid.org/0000-0003-2036-5528 Igor Karyakin (iD https://orcid.org/0000-0002-4543-1870 Pascual López-López iD https://orcid.org/0000-0001-5269-652X Thomas Mueller (iD https://orcid.org/0000-0001-9305-7716 Javier de la Puente (iD https://orcid.org/0000-0003-0207-0005 Nir Sapir iD https://orcid.org/0000-0002-2477-0515 Çağan H. Şekercioğlu (iD https://orcid.org/0000-0003-3193-0377 T. Scott Sillett (iD https://orcid.org/0000-0002-7486-0076 José Tavares iD https://orcid.org/0000-0003-2660-071X Peter P. Marra iD https://orcid.org/0000-0002-0508-7577

\section{REFERENCES}

Agostini, N., Panuccio, M., \& Pasquaretta, C. (2015). Morphology, flight performance, and water crossing tendencies of Afro-Palearctic raptors during migration. Current Zoology, 61(6), 951-958. https://doi. org/10.1093/czoolo/61.6.951
Alerstam, T., \& Hedenstrom, A. (1998). The development of bird migration theory. Journal of Avian Biology, 29(4), 343. https://doi.org/ $10.2307 / 3677155$

Anderson, D., Arkumarev, V., Bildstein, K., Botha, A., Bowden, C. G. R., Davies, M., Duriez, O., Forbes, N. A., Godino, A., Green, R., Krüger, S., Lambertucci, S. A., Orr-Ewing, D., Parish, C. N., Parry-Jones, J., \& Weston, E. (2020). A practical guide to methods for attaching research devices to vultures and condors. Vulture News, 78a(August), 1-72.

Arkumarev, V., Dobrev, V., Stoychev, S., Dobrev, D., Demerdzhiev, D., \& Nikolov, S. C. (2018). Breeding performance and population trend of the Egyptian Vulture Neophron percnopterus in Bulgaria: Conservation implications. Ornis Fennica, 95(3), 115-127.

Arrondo, E., Sanz-Aguilar, A., Pérez-García, J. M., Cortés-Avizanda, A., Sánchez-Zapata, J. A., \& Donázar, J. A. (2020). Landscape anthropization shapes the survival of a top avian scavenger. Biodiversity and Conservation, 29(4), 1411-1425. https://doi.org/10.1007/s10531020-01942-6

Banner, K. M., Irvine, K. M., \& Rodhouse, T. J. (2020). The use of Bayesian priors in Ecology: The good, the bad and the not great. Methods in Ecology and Evolution, 11(8), 882-889. https://doi.org/10.1111/2041210X.13407

Berthold, P. (2001). Bird migration: A general survey. Oxford University Press.

BirdLife International. (2020). Birdlife Data Zone. Retrieved from http:// www.birdlife.org/datazone/home

Bodey, T. W., Cleasby, I. R., Bell, F., Parr, N., Schultz, A., Votier, S. C., $\&$ Bearhop, S. (2018). A phylogenetically controlled meta-analysis of biologging device effects on birds: Deleterious effects and a call for more standardized reporting of study data. Methods in Ecology and Evolution, 9(4), 946-955. https://doi.org/10.1111/2041-210X.12934

Brooks, S. P., \& Gelman, A. (1998). General methods for monitoring convergence of iterative simulations)? Journal of Computational and Graphical Statistics, 7(4), 434-455. https://doi.org/10.1080/10618 600.1998.10474787

Calenge, C. (2006). The package 'adehabitat' for the R software: A tool for the analysis of space and habitat use by animals. Ecological Modelling, 197(3-4), 516-519. https://doi.org/10.1016/j.ecolmodel. 2006.03.017

Ceccolini, G., Cenerini, A., \& Aebischer, A. (2009). Migration and wintering of released Italian Egyptian Vultures Neophron percnopterus. Avocetta, 33, 71-74.

Chantepie, S., Teplitsky, C., Pavard, S., Sarrazin, F., Descaves, B., Lecuyer, P., \& Robert, A. (2016). Age-related variation and temporal patterns in the survival of a long-lived scavenger. Oikos, 125(2), 167-178. https://doi.org/10.1111/oik.02216

Cheng, Y., Fiedler, W., Wikelski, M., \& Flack, A. (2019). 'Closer-to-home' strategy benefits juvenile survival in a long-distance migratory bird. Ecology and Evolution, 9(16), 8945-8952. https://doi.org/10.1002/ ece3.5395

Crone, E. E. (2001). Is survivorship a better fitness surrogate than fecundity? Evolution, 55(12), 2611.

Del Moral, J. C., \& Molina, B. (Eds.). (2018). El alimoche común en España. SEO/BirdLife.

Duriez, O., Ens, B. J., Choquet, R., Pradel, R., \& Klaassen, M. (2012). Comparing the seasonal survival of resident and migratory oystercatchers: Carry-over effects of habitat quality and weather conditions. Oikos, 121(6), 862-873. https://doi.org/10.1111/j.1600-0706. 2012.20326. $x$

Duriez, O., Peron, G., Gremillet, D., Sforzi, A., \& Monti, F. (2018). Migrating ospreys use thermal uplift over the open sea. Biology Letters, 14(12), https://doi.org/10.1098/rsbl.2018.0687

Efrat, R., Hatzofe, O., \& Nathan, R. (2019). Landscape-dependent time versus energy optimizations in pelicans migrating through a large ecological barrier. Functional Ecology, 33(11), 2161-2171. https://doi. org/10.1111/1365-2435.13426 
Evans, R. J., Wilson, J. D., Amar, A., Douse, A., MacLennan, A., Ratcliffe, N., \& Whitfield, P. D. (2009). Growth and demography of a reintroduced population of White-tailed Eagles Haliaeetus albicilla. Ibis, 151, 244-254. https://doi.org/10.1111/j.1474-919X.2009.00908.x

Genovart, M., Pradel, R., \& Oro, D. (2012). Exploiting uncertain ecological fieldwork data with multi-event capture-recapture modelling: An example with bird sex assignment. Journal of Animal Ecology, 81(5), 970-977. https://doi.org/10.1111/j.1365-2656.2012.01991.x

Grande, J. M., Serrano, D., Tavecchia, G., Carrete, M., Ceballos, O., DíazDelgado, R., Tella, J. L., \& Donázar, J. A. (2009). Survival in a longlived territorial migrant: Effects of life-history traits and ecological conditions in wintering and breeding areas. Oikos, 118(4), 580-590. https://doi.org/10.1111/j.1600-0706.2008.17218.x

Karimov, T., \& Mammadov, A. (2019). The status of vultures Neophron percnopterus, Gypaetus barbatus, Gyps fulvus, Aegypius monachus (Accipitriformes) in Azerbaijan. Ukrainian Journal of Ecology, 9(4), 565-570. https://doi.org/10.15421/2019_791

Karyakin, I., Bekmansurov, R., Nikolenko, E., \& Dzhamirzoev, G. (2018). Monitoring results from the breeding group of Egyptian Vulture at Narat-Tyube Ridge and GPS/GSM tracking data from juvenile Egyptian Vultures (Republic of Dagestan, Russia). Raptors Conservation, 36, 108-135. https://doi.org/10.19074/1814-8654-2018-36-108-135

Kellner, K. F. (2016). jagsUl: A Wrapper Around 'rjags' to Streamline 'JAGS' Analyses version 1.5.1 from CRAN. Retrieved from https://rdrr.io/ cran/jagsUI/

Klaassen, R. H., Hake, M., Strandberg, R., Koks, B. J., Trierweiler, C., Exo, K.-M., \& Alerstam, T. (2014). When and where does mortality occur in migratory birds? Direct evidence from long-term satellite tracking of raptors. Journal of Animal Ecology, 83, 176-184. https://doi. org $/ 10.5061 /$ dryad.ds388

Kranstauber, B., Cameron, A., Weinzerl, R., Fountain, T., Tilak, S., Wikelski, M., \& Kays, R. (2011). The Movebank data model for animal tracking. Environmental Modelling and Software, 26(6), 834-835. https://doi.org/10.1016/j.envsoft.2010.12.005

Lack, D. (1954). The natural regulation of animal numbers. Clarendon Press. Lebreton, J. D., Burnham, K. P., Clobert, J., \& Anderson, D. R. (1992). Modeling survival and testing biological hypotheses using marked animals: A unified approach with case studies. Ecological Monographs, 62(1), 67-118. https://doi.org/10.2307/2937171

Liberatori, F., \& Penteriani, V. (2001). A long-term analysis of the declining population of the Egyptian vulture in the Italian peninsula: Distribution, habitat preference, productivity and conservation implications. Biological Conservation, 101, 381-389. https://doi. org/10.1016/S0006-3207(01)00086-6

Lok, T., Overdijk, O., \& Piersma, T. (2015). The cost of migration: Spoonbills suffer higher mortality during trans-Saharan spring migrations only. Biology Letters, 11(1). https://doi.org/10.1098/rsbl.2014.0944

Marra, P. P., Cohen, E. B., Loss, S. R., Rutter, J. E., \& Tonra, C. M. (2015). A call for full annual cycle research in animal ecology. Biology Letters, 11(8). https://doi.org/10.1098/rsbl.2015.0552

Mayrose, A., Labinger, Z., Steinitz, O., Hatzofe, O., Haviv, E., Perlman, Y., Alon, D., \& Leader, N. (2017). The red book of birds in Israel. In A. Mayrose, G. Vin, Z. Labinger, \& O. Steinitz (Eds.), Israel Nature and Parks Authority and the Society for the Protection of Nature in Israel.

McNamara, J. M., Barta, Z., Wikelski, M., \& Houston, A. I. (2008). A theoretical investigation of the effect of latitude on avian life histories. The American Naturalist, 172(3), 331-345. https://doi. org/10.1086/589886

Mihoub, J. B., Princé, K., Duriez, O., Lécuyer, P., Eliotout, B., \& Sarrazin, F. (2014). Comparing the effects of release methods on survival of the Eurasian black vulture Aegypius monachus reintroduced in France. Oryx, 48(1), 106-115. https://doi.org/10.1017/S003060531 2000981

Millon, A., Danovaro, C., Printemps, T., Leroux, A. B., Schlaich, A. E., Villers, A., Bourrioux, J.-L., \& Bretagnolle, V. (2019). Disentangling the effects of environmental conditions on wintering and breeding grounds on age-specific survival rates in a trans-Saharan migratory raptor. Journal of Avian Biology, 50(9). https://doi.org/10.1111/ jav. 02233

Monti, F., Grémillet, D., Sforzi, A., Sammuri, G., Dominici, J. M., Triay Bagur, R., Muñoz Navarro, A., Fusani, L., \& Duriez, O. (2018). Migration and wintering strategies in vulnerable Mediterranean Osprey populations. Ibis, 160(3), 554-567. https://doi.org/10.1111/ ibi.12567

Morant, J., Abad-Gómez, J. M., Álvarez, T., Sánchez, Á., Zuberogoitia, I., \& López-López, P. (2020). Winter movement patterns of a globally endangered avian scavenger in south-western Europe. Scientific Reports, 10(1), 1-11. https://doi.org/10.1038/s41598-020-74333-0

Nicoll, M. A. C., Jones, C. G., \& Norris, K. (2004). Comparison of survival rates of captive-reared and wild-bred Mauritius kestrels (Falco punctatus) in a re-introduced population. Biological Conservation, 118(4), 539-548. https://doi.org/10.1016/j.biocon.2003.09.028

Nisbet, I. C. T. (2001). Detecting and measuring senescence in wild birds: Experience with long-lived seabirds. Experimental Gerontology, 36(46), 833-843. https://doi.org/10.1016/S0531-5565(00)00244-8

Oppel, S. (2021). Data from: steffenoppel/EGVUsurvival: Egyptian Vulture survival analysis from satellite telemetry (Version v3.0). Zenodo, https://doi.org/10.5281/zenodo.4514124

Oppel, S., Dobrev, V., Arkumarev, V., Saravia, V., Bounas, A., Kret, E., Velevski, M., Stoychev, S., \& Nikolov, S. C. (2015). High juvenile mortality during migration in a declining population of a long-distance migratory raptor. Ibis, 157(3), 545-557. https://doi.org/10.1111/ ibi.12258

Oppel, S., \& Margalida, A. (2020). Egyptian vulture. In R. P. B. Keller, V. Herrando, S. Voříšek, P. Franch, M. Kipson, M. Milanesi, P. Martí, D. Anton, M. Klvaňová, A. Kalyakin, M. V. Bauer, \& H.-G. Foppen (Eds.), European Breeding Bird Atlas 2: Distribution, Abundance and Change. European Bird Census Council \& Lynx Edicions.

Panuccio, M., Agostini, N., \& Premuda, G. (2012). Ecological barriers promote risk minimisation and social learning in migrating short-toed snake eagles. Ethology Ecology and Evolution, 24(1), 74-80. https:// doi.org/10.1080/03949370.2011.583692

Phipps, W. L., López-López, P., Buechley, E. R., Oppel, S., Álvarez, E., Arkumarev, V., Bekmansurov, R., Berger-Tal, O., Bermejo, A., Bounas, A., Alanís, I. C., de la Puente, J., Dobrev, V., Duriez, O., Efrat, R., Fréchet, G., García, J., Galán, M., García-Ripollés, C., ... Vallverdú, N. (2019). Spatial and Temporal Variability in Migration of a Soaring Raptor Across Three Continents. Frontiers in Ecology and Evolution, 7(September), 1-14. https://doi.org/10.3389/fevo.2019.00323

Plummer, M. (2015). JAGS version 4.0.0 user manual. (August), (pp. 1-31). Retrieved from http://ftp.tw.freebsd.org/distfiles/mcmc-jags/jags_ user_manual.pdf

R Core Team. (2019). R: A language and environment for statistical computing. Retrieved from http://www.r-project.org/

Rappole, J., \& Jones, P. (2002). Evolution of old and new world migration systems. Ardea, 90(3), 525-538. Retrieved from http://cat.inist.fr/?aModele $=$ afficheN\&cpsidt $=14959394$

Robinson, R. A., Meier, C. M., Witvliet, W., Kéry, M., \& Schaub, M. (2020). Survival varies seasonally in a migratory bird: Linkages between breeding and non-breeding periods. Journal of Animal Ecology, 89(9), 2111-2121. https://doi.org/10.1111/1365-2656.13250

Rockwell, S. M., Wunderle, J. M., Sillett, T. S., Bocetti, C. I., Ewert, D. N., Currie, D., White, J. D., \& Marra, P. P. (2017). Seasonal survival estimation for a long-distance migratory bird and the influence of winter precipitation. Oecologia, 183(3), 715-726. https://doi.org/10.1007/ s00442-016-3788-x

Rotics, S., Kaatz, M., Resheff, Y. S., Turjeman, S. F., Zurell, D., Sapir, N., Eggers, U., Flack, A., Fiedler, W., Jeltsch, F., Wikelski, M., \& Nathan, R. (2016). The challenges of the first migration: Movement and behaviour of juvenile vs. adult white storks with insights regarding 
juvenile mortality. Journal of Animal Ecology, 85, 938-947. https://doi. org/10.1111/1365-2656.12525

Rushing, C. S., Hostetler, J. A., Sillett, T. S., Marra, P. P., Rotenberg, J. A., $\&$ Ryder, T. B. (2017). Spatial and temporal drivers of avian population dynamics across the annual cycle. Ecology, 98(11), 2837-2850. https://doi.org/10.1002/ecy.1967

Sæther, B. E., \& Bakke, Ø. (2000). Avian life history variation and contribution of demographic traits to the population growth rate. Ecology, 81(3), 642-653. https://doi.org/10.2307/177366

Salewski, V., \& Bruderer, B. (2007). The evolution of bird migration - A synthesis. Naturwissenschaften, 94(4), 268-279. https://doi. org/10.1007/s00114-006-0186-y

Sanderson, F. J., Donald, P. F., Pain, D. J., Burfield, I. J., \& van Bommel, F. P. J. (2006). Long-term population declines in Afro-Palearctic migrant birds. Biological Conservation, 131(1), 93-105. https://doi. org/10.1016/J.BIOCON.2006.02.008

Sanz-Aguilar, A., Cortés-Avizanda, A., Serrano, D., Blanco, G., Ceballos, O., Grande, J. M., Tella, J. L., \& Donázar, J. A. (2017). Sex- and agedependent patterns of survival and breeding success in a long-lived endangered avian scavenger. Scientific Reports, 7(January), 40204. https://doi.org/10.1038/srep40204

Sanz-Aguilar, A., De Pablo, F., \& Donázar, J. A. (2015). Age-dependent survival of island vs. mainland populations of two avian scavengers: Delving into migration costs. Oecologia, 179(2), 405-414. https://doi. org/10.1007/s00442-015-3355-x

Schaub, M., \& Royle, J. A. (2014). Estimating true instead of apparent survival using spatial Cormack-Jolly-Seber models. Methods in Ecology and Evolution, 5(12), 1316-1326. https://doi.org/10.1111/2041210X.12134

Senner, N. R., Verhoeven, M. A., Abad-Gómez, J. M., Alves, J. A., Hooijmeijer, J. C. E. W., Howison, R. A., Kentie, R., Loonstra, A. H. J., Masero, J. A., Rocha, A., Stager, M., \& Piersma, T. (2019). High migratory survival and highly variable migratory behavior in black-tailed godwits. Frontiers in Ecology and Evolution, 7(96), 1-11. https://doi. org/10.3389/fevo.2019.00096

Sergio, F., Tanferna, A., Blas, J., Blanco, G., \& Hiraldo, F. (2019). Reliable methods for identifying animal deaths in GPS- and satellite-tracking data: Review, testing, and calibration. Journal of Applied Ecology, 56(3), 562-572. https://doi.org/10.1111/1365-2664.13294

Sergio, F., Tanferna, A., De Stephanis, R., Jiménez, L. L., Blas, J., Tavecchia, G., Preatoni, D., \& Hiraldo, F. (2014). Individual improvements and selective mortality shape lifelong migratory performance. Nature, 515(7527), 410-413. https://doi.org/10.1038/natur e13696

Sergio, F., Tavecchia, G., Tanferna, A., Blas, J., Blanco, G., \& Hiraldo, F. (2019). When and where mortality occurs throughout the annual cycle changes with age in a migratory bird: Individual vs population implications. Scientific Reports, 9(17352), 1-8. https://doi org/10.1038/s41598-019-54026-z

Sergio, F., Tavecchia, G., Tanferna, A., López Jiménez, L., Blas, J., De Stephanis, R., Marchant, T. A., Kumar, N., \& Hiraldo, F. (2015). No effect of satellite tagging on survival, recruitment, longevity, productivity and social dominance of a raptor, and the provisioning and condition of its offspring. Journal of Applied Ecology, 52(6), 16651675. https://doi.org/10.1111/1365-2664.12520

Sillett, T. S., \& Holmes, R. T. (2002). Variation in survivorship of a migratory songbird throughout its annual cycle. Journal of Animal Ecology, 71(2), 296-308. https://doi.org/10.1046/j.1365-2656.2002.00599.x

Smart, J., Amar, A., Sim, I. M., Etheridge, B., Cameron, D., Christie, G., \& Wilson, J. D. (2010). Illegal killing slows population recovery of a re-introduced raptor of high conservation concern - The red kite Milvus milvus. Biological Conservation, 143(5), 1278-1286. https://doi. org/10.1016/j.biocon.2010.03.002

Sutherland, W. J. (1996). From individual behaviour to population ecology. Oxford University Press.

Swift, R. J., Rodewald, A. D., Johnson, J. A., Andres, B. A., \& Senner, N. R. (2020). Seasonal survival and reversible state effects in a longdistance migratory shorebird. Journal of Animal Ecology, 89(9), 20432055. https://doi.org/10.1111/1365-2656.13246

Velevski, M., Nikolov, S. C., Hallmann, B., Dobrev, V., Sidiropoulos, L., Saravia, V., Tsiakiris, R., Arkumarev, V., Galanaki, A., Kominos, T., Stara, K., Kret, E., Grubac, B., Lisicanec, E., Kastritis, T., Vavylis, D., Topi, M., Hoxha, S., Bledi, H., \& Oppel, S. (2015). Population decline and range contraction of the Egyptian Vulture Neophron percnopterus in the Balkan Peninsula. Bird Conservation International, 25(4), 440450. https://doi.org/10.1017/S0959270914000343

Vickery, J. A., Ewing, S. R., Smith, K. W., Pain, D. J., Bairlein, F., Škorpilová, J., \& Gregory, R. D. (2014). The decline of Afro-Palaearctic migrants and an assessment of potential causes. Ibis, 156(1), 1-22. https://doi. org/10.1111/ibi.12118

Weber, T. P., \& Dingle, H. (1996). Migration: The biology of life on the move (2nd ed.). https://doi.org/10.2307/2404896

Wilcove, D. S., \& Wikelski, M. (2008). Going, going, gone: Is animal migration disappearing? PLoS Biology, 6(7), 1361-1364. https://doi. org/10.1371/journal.pbio.0060188

Zink, R. M. (2002). Towards a framework for understanding the evolution of avian migration. Journal of Avian Biology, 33(4), 433-436. https:// doi.org/10.1034/j.1600-048X.2002.03081.X

Zúñiga, D., Gager, Y., Kokko, H., Fudickar, A. M., Schmidt, A., NaefDaenzer, B., Wikelski, M., \& Partecke, J. (2017). Migration confers winter survival benefits in a partially migratory songbird. Elife, 6, 112. https://doi.org/10.7554/eLife.28123

\section{SUPPORTING INFORMATION}

Additional supporting information may be found online in the Supporting Information section.

How to cite this article: Buechley ER, Oppel S, Efrat R, et al Differential survival throughout the full annual cycle of a migratory bird presents a life-history trade-off. J Anim Ecol. 2021;90:1228-1238. https://doi.org/10.1111/1365-2656.13449 